\title{
Motor Unit Number Estimation in Neuromuscular Disease
}

\author{
Omid Rashidipour, K. Ming Chan
}

\begin{abstract}
Motor unit number estimation (MUNE) is an electrophysiological method designed to quantify motor unit loss in target muscles of interest. Most of the techniques are noninvasive and are therefore well suited for longitudinal monitoring. In this brief review, we describe the more commonly used techniques and their applications in amyotrophic lateral sclerosis, poliomyelitis, spinal muscular atrophy and hereditary sensorimotor neuropathies. Findings in some of these studies offer important pathophysiological insights. Since conventional electrophysiologic methods are not sensible measures of motor neuronal loss, MUNE could play a potentially important role in the diagnosis, monitoring of disease progression and response to treatment in neuromuscular diseases in which motor unit loss is a major feature.
\end{abstract}

RÉSUMÉ: Estimation du nombre d'unités motrices dans les maladies neuromusculaires. L'estimation du nombre d'unités motrices (ENUM) est une méthode électrophysiologique pour quantifier la perte d'unités motrices dans les muscles étudiés. La plupart des techniques non effractives sont donc appropriées pour la surveillance longitudinale. Dans cette courte revue, nous décrivons les techniques les plus fréquemment utilisées et leur application dans la sclérose latérale amyotrophique, la poliomyélite, l'atrophie musculaire spinale et les neuropathies sensitivomotrices héréditaires. Les observations provenant de ces études fournissent des indices physiopathologiques importants. Étant donné que les méthodes électrophysiologiques conventionnelles ne constituent pas une mesure sensible de la perte de neurones moteurs, l'ENUM pourrait jouer un rôle important dans le diagnostic, la surveillance de la progression de la maladie et la réponse au traitement dans les maladies neuromusculaires où la perte d'unités motrices est un élément important.

Can. J. Neurol. Sci. 2008; 35: 153-159

Motoneuronal death is a major feature in many neuromuscular diseases. As a result of the remarkable ability of motor axons to sprout and to regenerate, the extent of motoneuronal loss often does not become clinically apparent until the loss is well advanced. This discrepancy is particularly striking in chronic, slowly progressive disorders in which surviving motoneurons have ample time to expand their innervation field. In those conditions, motor unit number estimation (MUNE) can be particularly valuable in gauging disease severity, disease progression and treatment response.

In this review, we will briefly describe the commonly used MUNE methods. Their applications in neuromuscular diseases and the findings from these studies will be described in detail.

\section{BASIC CONCEPTS IN MUNES}

Only in terminal stages of motor neuronal or axonal diseases when a few motor units remain is it possible to count all the motor units within a muscle. In healthy subjects who have roughly 100 motor units per intrinsic hand muscle,,$^{1,2}$ it is clearly impossible and impractical by any currently available noninvasive physiological means that can be used on awake human subjects to identify and count all the motor units within a muscle. McComas was the first to introduce the concept of estimation of motor unit number by electrophysiological means. ${ }^{3}$ To circumvent the impasse where the number of motor units is

From the Centre for Neuroscience, Division of Physical Medicine and Rehabilitation, Faculty of Medicine, University of Alberta, Edmonton, Alberta, Canada. Received July 27, 2007. Final Revisions Submitted November 8, 2007. Reprint requests to: K.M. Chan, 513 Heritage Medical Research Centre, University of Alberta, Edmonton, Alberta, Canada, T6G 2S2 
too large to render direct counting possible, one has to first determine the size of the surface detected action potential generated by all the motor units in the muscle in response to a supramaximal stimulus delivered to the motor nerve. The next step is to draw from all the available motor units within a muscle, a small but representative sample of motor units, from which the average size of the surface detected motor unit action potential may be determined. An estimate of the number of motor units within a muscle or muscle group may then be determined by simple division:

MUNE $=\frac{\text { size of the maximum compound muscle action potential }}{\text { size of the average surface detected motor unit action potential }}$

To meet the challenge of creating a practical and reliable method for estimating the number of motor units, a number of methods have been devised. They may be distinguished from one another by how the sample of motor units used to derive the average motor unit action potential size is obtained.

Although many of those methods have been shown to be valid and robust, the adaptation of MUNE as a clinical outcome measure is not without difficulty along the way. Indeed, an early setback is the controversy caused by the proposal of the "sick motoneuron" hypothesis in patients with muscular dystrophies. ${ }^{4}$ Although the observation of decreased motor unit number in those patients through segmental denervation of the muscle fibres was correct, this does not necessarily imply causality, as later acknowledged by McComas. ${ }^{5}$ Indeed, through later discoveries such as dystrophin, this hypothesis was discredited. However, this error of interpretation in no way interferes with the validity of the underlying concept of MUNE. Indeed, results obtained from many of these electrophysiological MUNE methods are supported by other means of estimating motor unit numbers. ${ }^{6-8}$

Instead of providing an exhaustive account of all the MUNE methods, only those that have been frequently used to study neuromuscular diseases will be described here.

\section{Manual InCREmental Stimulation}

This is the original MUNE technique proposed by McComas in $1971 .^{3}$ With this method, an electrical stimulus is delivered to a motor nerve at a frequency of $1 \mathrm{~Hz}$ and the intensity gradually increased until the threshold of the lowest threshold axon at the chosen site for stimulation is reached. Provided the range of stimulus intensity of this axon is sufficiently separate from the higher threshold motor axons, small increases and reductions in the stimulus intensity close to its threshold will be accompanied by the appearance or disappearance of the associated motor unit action potential. The latter "all or none" response is the electrical "sign" of threshold stimulation of a single axon. Further increases in the intensity of successive stimuli delivered to the nerve are accompanied by increases in the frequency with which the "all" response occurs to the point at which the "all" response occurs every time in response to successive stimuli.

As the stimulus intensity is further increased, eventually the threshold of the next higher threshold motor axon is reached. In this case the "all" response corresponding to activation of the next motor axon is signaled by the addition to the motor unit action potential of the lowest threshold motor axon, plus that of

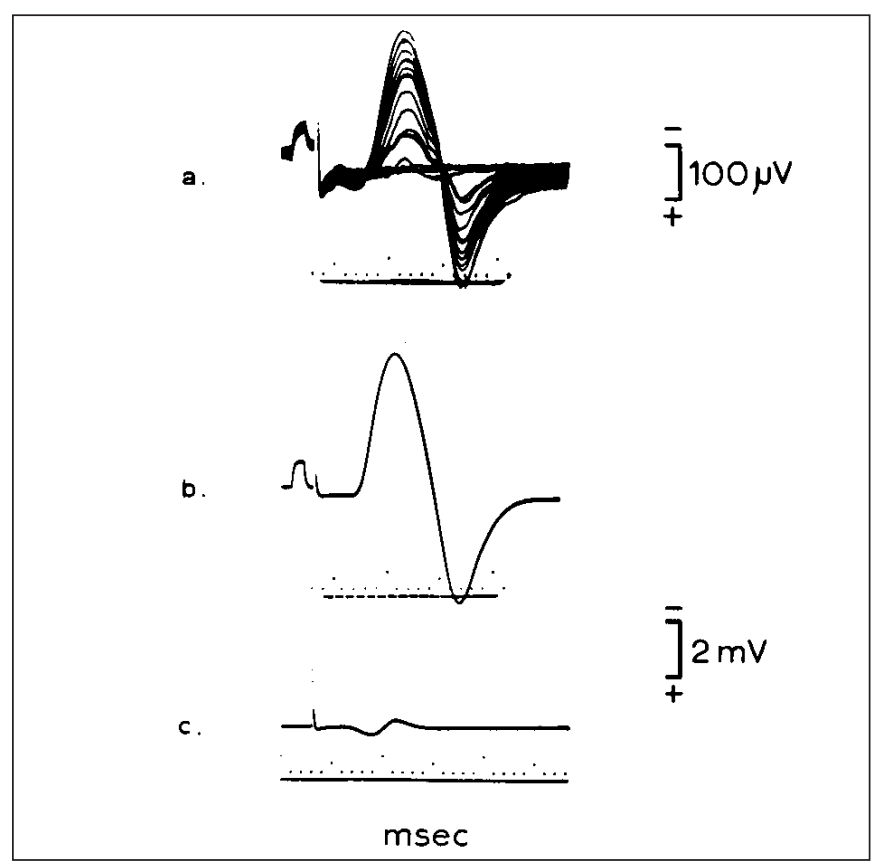

Figure 1: Manual Incremental Stimulation technique. (a) Stepwise incremental responses recorded over the extensor digitorum brevis muscle $(E D B)$ from increasing stimulus intensities. In this example, ten steps are elicited from which the average motor unit action potential amplitude can be obtained through division of the total amplitude of all the steps by the number of steps. (b) Maximum M-potential recorded over the same area. The motor unit number estimate is calculated through division of the amplitude of the maximum M-potential by that of the average motor unit action potential. The elicited responses are solely generated by the EDB muscle as confirmed by the recording over the first dorsal interosseus muscle (c) in the foot where only a very small volume conducted response is found (reproduced from McComas et al, 1971). ${ }^{3}$

the next motor axon. Further increase in the stimulus intensity activate successively higher threshold motor axons and with the addition of their associated motor unit action potentials the "M" potential grows in reproducible stepwise increments (Figure 1). The average size of the motor unit action potentials from such a sample may then be derived simply by division of the sum of the motor unit action potentials associated with stimulation of each of the successively higher threshold axons by the number of increment steps in the M-potential. The MUNE is then calculated by division of the maximum M-potential by the average surface detected motor unit potential size.

One major drawback of this MUNE method is attributable to the fact that the threshold of nerve fiber excitation is not a discrete value. Rather, the probability of motor unit activation spreads over a range that frequently overlaps between neighboring motor axons. Therefore, a successive step elicited by a higher intensity pulse does not necessarily signify the combined activation of the original lower threshold motor unit with an additional motor unit. Rather, it could be due to activation of another motor unit with slightly higher but 
overlapping threshold instead of the original lower threshold motor unit. This phenomenon, termed "alternation", can lead to overestimation of the motor unit number. ${ }^{9,10}$ To avoid this pitfall, other subsequent methods described below were derived.

\section{Multiple Point Stimulation}

In this technique, the motor nerve is stimulated at many sites along the course of the nerve, as shown in Figure 2. ${ }^{2}$ Finely graded stimuli are used to identify the lowest threshold motor axon as signaled by the appearance of the "all or none" response of the associated surface detected motor unit action potential. For each surface detected motor unit action potential to be accepted as representing a single motor unit, there must be no change in the shape or latency of the detected response in response to successive stimuli which might suggest the presence of two or more axons with overlapping thresholds. By only accepting the lowest threshold motor units at each stimulation site, the uncertainty associated with alternation is avoided. The method, in practiced hands makes it possible in healthy subjects to collect anywhere from 12-20 motor unit action potentials within a reasonably short time. From these, a sample size sufficient to provide a reliable average motor unit action potential size from which the motor unit estimate may be derived.
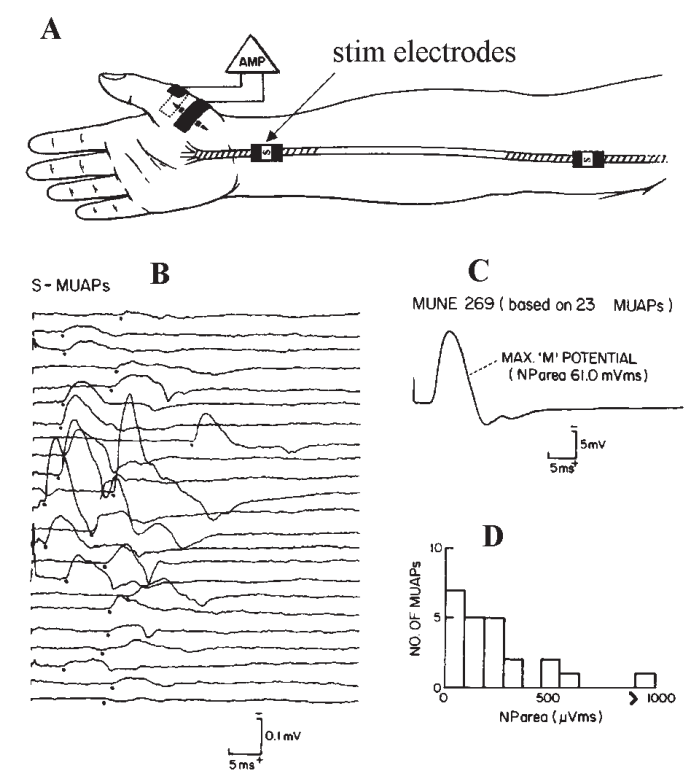

C

MUNE 269 (based on 23 MUAPS)
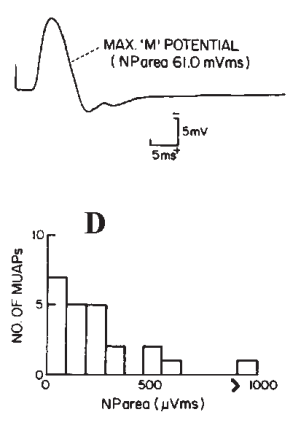

Figure 2: Multiple Point Stimulation technique. A. Experimental setup. The shaded area denotes superficial portion of the median nerve accessible to surface stimulation. B. A collection of surface detected motor unit action potentials ( $S$-MUAPS) recorded from the median innervated thenar muscle group in a healthy subject. The dots signify onset of the action potentials. The average motor unit action potential is calculated from these S-MUAPs using data point by data point averaging. D. As to be expected in healthy muscles, there is a predominance of small motor units (modified from Doherty et al, 1995)..$^{10}$

\section{Spike-Triggered Averaging Method}

Unlike the previous methods in which electrical stimulation is used to stimulate the motor nerve, voluntary muscle contraction is used to activate the motor units. This method is designed to be used on proximal muscle groups where the deeply located nerve trunk cannot be easily reached by electrical stimulation. For recording, a needle EMG electrode is used to detect motor unit activation. ${ }^{11,12}$ The motor unit spike is used as a trigger source to ensemble-average the surface action potentials time locked with the MU. By changing the position of the needle, a sample of ten or more single motor unit action potentials are collected and the MUNE is calculated by dividing the average surface detected motor unit action potentials (SMUAP) into the maximum CMAP (Figure 3).

\section{Statistical Method}

Daube proposed that since the sizes of surface detected motor unit action potentials follow a Poisson distribution, the variance

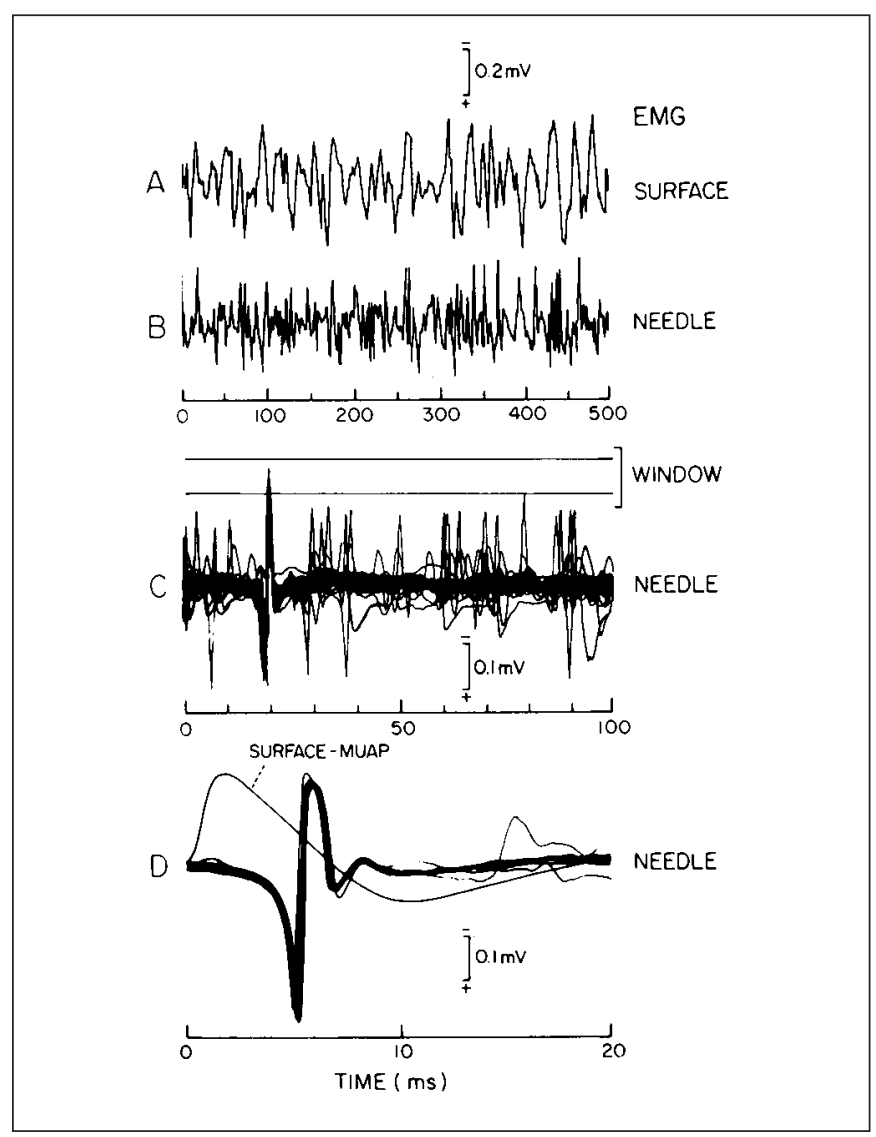

Figure 3: Spike-Triggered Averaging technique. In this figure, a concentric EMG needle electrode is inserted in the biceps brachii muscle. The voluntarily activated motor unit spike (shown in C) is used as a trigger source (detected by the discrimination window) to ensembleaverage the surface action potentials time locked to the motor unit spike (shown in D) (reproduced from Doherty et al, 1995). ${ }^{10}$ 
of the motor unit potential should be equal to the mean motor unit action potential. ${ }^{13}$ In this method, recording electrodes are applied as for standard nerve conduction studies, with the stimulating electrode taped over the innervating nerve. An initial scan is performed by delivering 30 computer-controlled stimuli at $1 \mathrm{~Hz}$ that increased in intensity at equally spaced increments from just below threshold to just maximal. The amplitude differences between successive responses determine the choice of stimulus intensities that will be utilized for each determination of mean motor unit action potential amplitude. A sequence of 30 submaximal stimuli is then given at each stimulus intensity. The inherent variability of the threshold of individual axons causes their intermittent firing and variations in the size of the compound muscle action potential (CMAP). Because the method is a statistical measurement, a somewhat different result is found with each series of stimuli. Therefore, multiple trials are needed to obtain an accurate measurement. The recording is stopped after four to nine trials if the standard error of the SMUP amplitudes is less than $10 \%$ of the mean. The same exercise is carried out at all the other pre-chosen stimulus intensity levels. The final MUNE is an average calculated from the MUNEs obtained from all the trials. Because of methodological concerns, a number of modifications have been proposed. ${ }^{14,15}$ Decrement of motor unit action potential with repetitive stimulation, if unrecognized, can have a major impact on the MUNE results. Because motor unit action potential decrement is liable to occur in dysfunctional motor units and that its presence cannot be discerned using the statistical method, results obtained by using this technique must be guarded. ${ }^{16}$ Because of this major concern, the statistical method in its present form, is no longer widely used.
Each of the above methods has their advantages and disadvantages, as listed in the Table. ${ }^{17}$ These render them better suited for some applications but not in others. In practice, currently the most widely used method for studying distal muscles is the multiple point stimulation technique while spiketriggered averaging is most commonly used for studying proximal muscles whose innervating nerve cannot easily be stimulated over a long distance. These methods have been shown to be reasonably reliable by different recent investigators. ${ }^{2,18-20}$ For example, test -retest reliability as measured by the Pearson's correlation coefficient of the multiple point stimulation technique, was between 0.8520 and $0.90 .{ }^{18}$ Using the decomposition enhanced spike triggered averaging technique, correlation coefficient of the test-retest MUNE results was $0.94 .{ }^{19}$

\section{Clinical apPlications IN NeURomuscular Diseases}

Among the different disorders, MUNE is particularly useful in chronic, slowly progressive disorder in which motoneuronal loss can be easily masked. For example, in an early study by Brown, ${ }^{21}$ MUNE was done on 19 patients with carpal tunnel syndrome. Out of the 12 patients who did not have any weakness or wasting of their thenar muscles, 8 had motor unit number estimate at least 2 standard deviation (SD) below age matched controls.

\section{Amyotrophic lateral sclerosis}

Of all the neuromuscular diseases, the most extensive application of MUNE is in amyotrophic lateral sclerosis (ALS).

Table: Advantages and disadvantages of motor unit number estimation methods

\begin{tabular}{|c|c|c|}
\hline Method & Advantages & Disadvantages \\
\hline Manual incremental stimulation & $\begin{array}{l}\text { 1. Applicable to any EMG system with storage } \\
\text { Oscilloscope function } \\
\text { 2. S-MUAPs collected at a single site of } \\
\text { stimulation } \\
\text { 3. Noninvasive } \\
\text { 4. Minimal patient cooperation required }\end{array}$ & $\begin{array}{l}\text { 1. Alternation (see text) } \\
\text { 2. Not applicable to proximal muscles } \\
\text { 3. Requires considerable operator } \\
\text { skill and experience }\end{array}$ \\
\hline Multiple-point stimulation & $\begin{array}{l}\text { 1. Noninvasive } \\
\text { 2. Threshold stimuli well tolerated } \\
\text { 3. Ability to recognize pathological features } \\
\text { of S-MUAP (e.g., decrement, repetitive firing) } \\
\text { 4. Minimal patient cooperation required }\end{array}$ & $\begin{array}{l}\text { 1. Requires considerable operator } \\
\text { skill and experience } \\
\text { 2. Not applicable to proximal muscles } \\
\text { 3. S-MUAPs not collected at a single } \\
\text { site of stimulation }\end{array}$ \\
\hline Spike-triggered averaging & $\begin{array}{l}\text { 1. Applicable to proximal and distal muscles } \\
\text { 2. Requires little operator skill } \\
\text { 3. Provides additional information from needle } \\
\text { EMG signal }\end{array}$ & $\begin{array}{l}\text { 1. Requires specific software } \\
\text { 2. Invasive because it requires } \\
\text { needle electrode } \\
\text { 3. Time consuming } \\
\text { 4. S-MUAPs not collected at a single } \\
\text { site of stimulation } \\
\text { 5. Requires some patient cooperation }\end{array}$ \\
\hline
\end{tabular}

S-MUAPs denotes surface detected motor unit action potentials (adopted from Doherty and Brown, 2002). ${ }^{17}$ 
Since $\alpha$-motoneurons are one of the primary targets in ALS, MUNE provides a sensitive means of following disease progression. Indeed, of the 123 patients studied by Dantes and McComas, ${ }^{22}$ over $80 \%$ of them already had abnormally low motor unit number estimate in the median-innervated thenar muscles at the time of diagnosis (Figure 4). Furthermore, once a muscle became affected by the disease process, the average rate of motoneuronal loss was $50 \%$ every six months in the first year. At present, the major outcome measures used in ALS clinical trials are survival time, voluntary muscle strength, forced vital capacity and functional rating scales. While these are important functional parameters, they do not directly assess the underlying mechanism of disease progression in ALS. Therefore, it is perhaps not surprising that Bromberg and Larson ${ }^{23}$ found that correlation between the maximum voluntary contraction (MVC) strength and motor unit number estimation in the intrinsic hand muscles was rather weak. This discrepancy could be explained by the fact that muscle strength, at least initially, can be amply compensated through vigorous sprouting and reinnervation of denervated muscle fibers by the remaining motor axons. Felice was the first to show that MUNE was a more sensitive marker of disease progression in ALS than quantitative muscle strength testing, forced vital capacity and functional rating scale. ${ }^{24}$ These observations were subsequently confirmed by other studies. ${ }^{25-27}$ These findings have two important practical implications. First, at present, in many ALS clinical trials, patients with very slow rate of progression are often excluded because the chances of them showing a significant change in MVC and other conventional functional measures are small. However, with the use of a more sensitive measure such as MUNE, it may be possible that those patients can also be included in the study. Second, an advantage of using a more sensitive measure is that the length of the study can be potentially shortened-an important consideration in a rapidly fatal disease like ALS.

Shefner et al used statistical MUNE to investigate the efficacy of creatine and celecoxib in slowing the progression of ALS. ${ }^{16,28}$ They found that these drugs were not effective. Interestingly, the SMUP amplitude remained stable throughout the course of the disease which is not consistent with other human and animal studies. ${ }^{26,29}$ They attributed this to potential technical errors inherent in statistical MUNE that is biased toward selection of small motor units.

An interesting observation in ALS is that the thenar hand muscles often seem to be affected earlier and more severely than the hypothenar muscles. ${ }^{30}$ Kuwabara et $\mathrm{al}^{31}$ confirmed this by computing the ratio of APB/ADM MUNE and found that the APB muscle was disproportionately affected. Eisen suggested that this could be because thenar muscles receive a larger cortical outflow than the hypothenar muscles. ${ }^{32}$ Whether this is indeed the case is not clear as similarly disproportionate involvement of the thenar muscles has also been observed in other conditions including poliomyelitis and vincristine induced peripheral neuropathy. ${ }^{33}$

\section{Poliomyelitis}

Another application of MUNE is to define disease progression in post-polio patients. Because many of the symptoms that constitute post-polio syndrome are difficult to quantify, the definition of post-polio syndrome is still

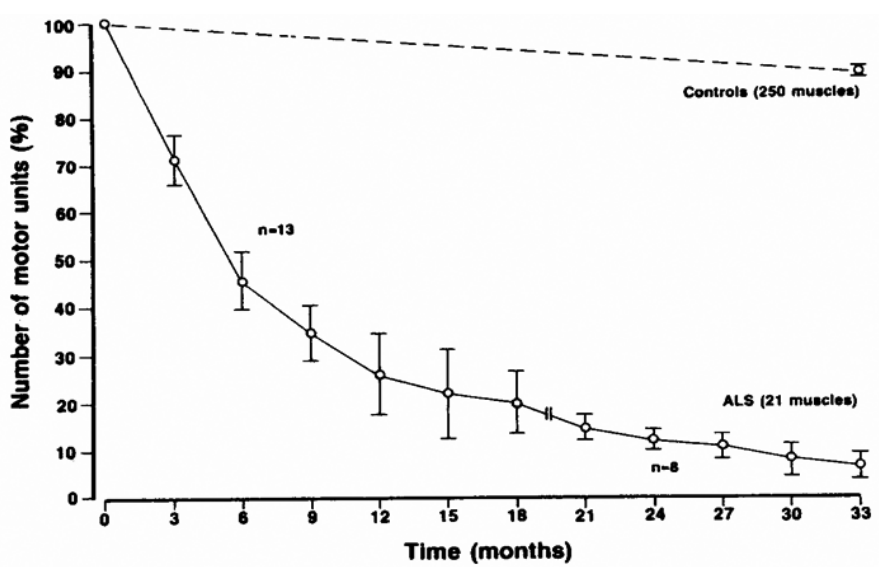

Figure 4: Rate of motor unit loss in ALS patients. In this group of ALS patients, there was a greater than 50\% loss of motor units every six months. In contrast, the total loss in healthy controls over the 33 month period was less than 10\% (reproduced from Dante and McComas, 1991). ${ }^{22}$

controversial. One of these symptoms is new weakness. Results from previous studies utilizing other electrophysiologic measures revealed conflicting findings on whether new motoneuronal loss is the cause of this symptom. Motor unit number estimation has helped to shed light on this. McComas et al studied 76 patients who had polio decades earlier. ${ }^{33}$ All except four developed new weakness. At the initial visit, in addition to $87 \%$ of muscles in the affected limbs that had reduced motor unit numbers, $65 \%$ of limbs that were not known to be affected also had significantly reduced motor unit numbers. A subset of 18 patients was studied a second time two years later. They were found to have an average of $13.4 \%$ reduction in motor unit number, a rate of motor unit loss that is twice that of healthy subjects of similar ages.

Sorenson et al followed 38 patients, chosen randomly from an original pool of 298 patients. ${ }^{34,35}$ Electrophysiological and manual muscle strength testing were done at baseline, 5 and 15 years later. They used statistical MUNE to study the median nerve innervated thenar muscles and peroneal nerve innervated extensor digitorum brevis (EDB) muscle. Neurological Disability Scale for Weakness (NDS-w) was used for quantifying muscle strength. The summated MUNE in both muscle groups declined from 407 at baseline to 226 at 15 years $(p<0.001)$. In accordance with the decline in motor unit numbers, the NDS-w also deteriorated from a mean of 18 to 21 over the same period $(\mathrm{p}=0.01)$. Both the upper and lower extremities demonstrated a significant correlation between the MUNE and the corresponding limb NDS-w score.

Another controversial question in post-polio patients is what the safety limit of strength training is in these patients. Results from published studies based on voluntary strength measurements are inconclusive. We evaluated the impact of strength training on motor functions as well as the potential detrimental effect on motor unit survival in the median 
innervated thenar muscles in post polio patients. ${ }^{36}$ Ten post-polio patients with hand involvement were randomized to either the training or control group. The progressive resistance training program consisted of three sets of eight isometric contractions at $50-70 \%$ MVC, three times weekly for 12 weeks. Seven healthy elderly were also randomized and trained in a similar manner. Changes in the baseline parameters were monitored once every four weeks throughout the training period. The trained post-polio patients showed a significant improvement in their strength $(\mathrm{p}<$ $0.05)$. The magnitude of gain was greater than that seen in the healthy elderly (mean $\pm \mathrm{SE}=41 \pm 16 \%$ in the polio subjects vs. 29 $\pm 8 \%$ in the healthy controls). More importantly, the training did not adversely affect MU survival and the improvement was largely attributable to an increase in voluntary motor drive.

\section{Spinal muscular atrophy}

Spinal muscular atrophy (SMA) is characterized by a loss of lower motor neurons and can manifest symptoms in infancy and early childhood. It is divided into subtypes based on age of symptom onset and rapidity of progression or highest milestone achieved ${ }^{37}$ Clinically, with weakness and wasting predominately affecting proximal muscles, it is not surprising that motor unit numbers were found to be significantly reduced in the biceps brachii muscle in patients with SMA 2 and SMA $3 .{ }^{38}$ However, although less apparent, distinct motor unit loss was also present in distal hand muscles. ${ }^{39}$ Using the multiple point stimulation technique, Swoboda et al assessed the hypothenar muscles of 89 patients with SMA types 1, 2 and 3. In keeping with differences in their age of onset and speed of progression, the lowest motor unit number was found in SMA1, followed by SMA 2 and SMA 3. Although CMAP also followed a similar trend, the magnitude of change was substantially smaller. Indeed, the mean CMAP amplitude in patients with SMA 3 did not fall below the normal limits until the age of five while the MUNE was already distinctly abnormal before the age of two.

\section{Hereditary sensory motor neuropathy}

Charcot-Marie-Tooth (CMT) neuropathy comprises a heterogeneous group of inherited peripheral nerve diseases that can be transmitted through autosomal dominant, recessive or X-linked patterns. ${ }^{40,41}$ They result in either predominantly demyelination or axonal degeneration of the motor and sensory nerve fibres. Nerves with long axons innervating the distal upper and lower limbs are more severely affected. Routine electrodiagnostic studies and CMAP amplitude do not provide accurate information regarding the extent of axonal loss. Lawson et $\mathrm{al}^{42}$ and Lewis et $\mathrm{al}^{43}$ confirmed severe motor unit loss in the hypothenar muscles of CMT1A and CMT2 patients. However, results on the extent of proximal muscle involvement are less consistent. In Lawson et al's study, significant motor unit loss in the biceps-brachialis muscles was only found in CMT2 but not CMT1A patients. In contrast, Lewis et al found that motor unit loss occurred in both groups. The reason for this discrepancy is not clear at present and will therefore require further investigation.

\section{Conclusions}

Although interest has been shown by many investigators to use MUNE as an evaluation tool in ALS clinical trials and other neuromuscular diseases, the application of MUNE for those purposes is still relatively limited. There are a number of potential reasons for this. First, there are differences in the various MUNE methods, each with their own strengths and weaknesses. Therefore, the choice can be confusing and the selection in part depends on the muscle group being studied and the equipment available. In practice, the multiple point stimulation and spike triggered averaging have emerged as the more commonly used techniques. Second, excessive test-retest variability was a concern in some earlier studies. However, more recent studies have demonstrated acceptable test-retest reliability with refinement of the techniques. Lastly, programs needed to do MUNE were often confined to research lab or were only available on specific proprietary EMG machines. However, these programs are now becoming more readily available. Therefore, it is likely that MUNE will be more widely incorporated into clinical trials as part of the outcome measures in the future.

\section{REFERENCES}

1. Feinstein B, Lingegard B, Nyman E, Wohlfart G. Morphologic studies of motor units in normal human muscles. Acta Anat. 1955; 23: 127-42.

2. Doherty TJ, Brown WF. The estimated numbers and relative sizes of thenar motor units as selected by multiple point stimulation in young and older adults. Muscle Nerve. 1993; 16: 355-66.

3. McComas AJ, Fawcett PR, Campbell MJ, Sica RE. Electrophysiological estimation of the number of motor units within a human muscle. J Neurol Neurosurg Psychiatry. 1971; 34: 121-31.

4. McComas AJ, Sica REP, Campbell MJ. "Sick" motoneurones--a unifying concept of muscle disease. Lancet. 1971; 321-25.

5. McComas AJ. Motor-unit estimation: the beginning. J Clin Neurophysiol. 1995; 12: 560-4.

6. Arasaki K, Tamaki M, Hosoya Y, Kudo N. Validity of electromyograms and tension as a means of motor unit number estimation. Muscle Nerve. 1997; 20: 552-60.

7. Santo Neto H, de Carvalho VC, Marques MJ. Estimation of the number and size of human flexor digiti minimi muscle motor units using histological methods. Muscle Nerve. 1998; 21: $112-14$.

8. Major LA, Jones KE. Simulations of motor unit number estimation techniques. J Neural Eng. 2005; 2: 17-34.

9. Brown WF, Milner-Brown HS. Some electrical properties of motor units and their effects on the methods of estimating motor unit numbers. J Neurol Neurosurg Psychiatry. 1976; 39: 249-57.

10. Doherty T, Simmons Z, O'Connell B, Felice KJ, Conwit R, Chan $\mathrm{KM}$, et al. Methods for estimating the numbers of motor units in human muscles. J Clin Neurophysiol. 1995; 12: 565-84.

11. Brown WF, Strong MJ, Snow R. Methods for estimating numbers of motor units in biceps- brachialis muscles and losses of motor units with aging. Muscle Nerve. 1988; 11: 423-32.

12. Strong MJ, Brown WF, Hudson AJ, Snow R. Motor unit estimates in the biceps-brachialis in amyotrophic lateral sclerosis. Muscle Nerve. 1988; 11: 415-22.

13. Daube JR. Estimating the number of motor units in a muscle. J Clin Neurophysiol. 1995; 12: 585-94.

14. Shefner JM, Jillapalli D, Bradshaw DY. Reducing intersubject variability in motor unit number estimation. Muscle Nerve. 1999; 22: 1457-60.

15. Miller TM, Kogelnik AM, Olney RK. Proposed modification to data analysis for statistical motor unit number estimate. Muscle Nerve. 2004; 29: 700-6.

16. Shefner JM, Cudkowicz ME, Zhang H, Schoenfeld D, Jillapalli D. The use of statistical MUNE in a multicenter clinical trial. Muscle Nerve. 2004; 30: 463-9.

17. Doherty TJ, Brown WF. Motor unit number estimation: methods and applications. In: Brown WF, Bolton CF, Aminoff MJ, editors. Neuromuscular function and disease. Philadelphia, PA: W.B. Saunders; p. 274-90. 
18. Lomen-Hoerth C, Olney RK. Comparison of multiple point and statistical motor unit number estimation. Muscle Nerve. 2000; 23: $1525-33$.

19. Boe SG, Stashuk DW, Doherty TJ. Motor unit number estimation by decomposition-enhanced spike-triggered averaging: control data, test-retest reliability, and contractile level effects. Muscle Nerve. 2004; 29: 693-9.

20. Felice KJ. Thenar motor unit number estimates using the multiple point stimulation technique: reproducibility studies in ALS patients and normal subjects. Muscle Nerve. 1995; 18: 1412-16.

21. Brown WF. Thenar motor unit count estimates in the carpal tunnel syndrome. J Neurol Neurosurg Psychiatry. 1973; 36: 194-8.

22. Dantes M, McComas AJ. The extent and time course of motoneuron involvement in amyotrophic lateral sclerosis. Muscle Nerve. 1991; 14: 416-21.

23. Bromberg MB, Larson WL. Relationships between motor-unit number estimates and isometric strength in distal muscles in ALS/MND. J Neurol Sci. 1996; 139 Suppl: 38-42.

24. Felice KJ. A longitudinal study comparing thenar motor unit number estimates to other quantitative tests in patients with amyotrophic lateral sclerosis. Muscle Nerve. 1997; 20: 179-85.

25. Yuen EC, Olney RK. Longitudinal study of fiber density and motor unit number estimate in patients with amyotrophic lateral sclerosis. Neurology. 1997; 49: 573-8.

26. Arasaki K, Kato Y, Hyodo A, Ushijima R, Tamaki M. Longitudinal study of functional spinal alpha motor neuron loss in amyotrophic lateral sclerosis. Muscle Nerve. 2002; 25: 520-6.

27. Wang FC, Bouquiaux O, De Pasqua V, Delwaide PJ. Changes in motor unit numbers in patients with ALS: a longitudinal study using the adapted multiple point stimulation method. Amyotroph Lateral Scler Other Motor Neuron Disord. 2002; 3: 31-8.

28. Shefner JM, Cudkowicz ME, Zhang H, Schoenfeld D, Jillapalli D. Revised statistical motor unit number estimation in the Celecoxib/ALS trial. Muscle Nerve. 2007; 35: 228-34.

29. Shefner JM, Cudkowicz M, Brown RH, Jr. Motor unit number estimation predicts disease onset and survival in a transgenic mouse model of amyotrophic lateral sclerosis. Muscle Nerve. 2006; 34: 603-7.

30. Eisen A. Comment on the lower motor neuron hypothesis. Muscle Nerve. 1993; 16: 870-2.
31. Kuwabara S, Mizobuchi K, Ogawara K, Hattori T. Dissociated small hand muscle involvement in amyotrophic lateral sclerosis detected by motor unit number estimates. Muscle Nerve. 1999; 22: 870-3.

32. Eisen A, Weber M. The motor cortex and amyotrophic lateral sclerosis. Muscle Nerve. 2001; 24: 564-73.

33. McComas AJ, Quartly C, Griggs RC. Early and late losses of motor units after poliomyelitis. Brain. 1997; 120: 1415-21.

34. Sorenson EJ, Daube JR, Windebank AJ. Electrophysiological findings in a cohort of old polio survivors. J Peripher Nerv Syst. 2006; 11: 241-6.

35. Sorenson EJ, Daube JR, Windebank AJ. Motor unit number estimates correlate with strength in polio survivors. Muscle Nerve. 2006; 34: 608-13.

36. Chan KM, Amirjani N, Sumrain M, Clarke A, Strohschein FJ. Randomized controlled trial of strength training in post-polio patients. Muscle Nerve. 2003; 27: 332-8.

37. Iannaccone ST. Spinal muscular atrophy. [Review]. Sem Neurol. 1998; 18: 19-26.

38. Galea V, Fehlings D, Kirsch S, McComas A. Depletion and sizes of motor units in spinal muscular atrophy. Muscle Nerve. 2001; 24 : 1168-72.

39. Swoboda KJ, Prior TW, Scott CB, McNaught TP, Wride MC, Reyna SP, et al. Natural history of denervation in SMA: relation to age, SMN2 copy number, and function. Ann Neurol. 2005; 57 : 704-12.

40. Murakami T, Garcia CA, Reiter LT, Lupski JR. Charcot-MarieTooth disease and related inherited neuropathies. [Review]. Medicine. 1996; 75: 233-50.

41. Mendell JR. Charcot-Marie-Tooth neuropathies and related disorders. [Review]. Sem Neurol. 1998; 18: 41-7.

42. Lawson VH, Gordon SA, Bromberg MB. Assessment of axonal loss in Charcot-Marie-Tooth neuropathies. Exp Neurol. 2003; 184: 753-7.

43. Lewis RA, Li J, Fuerst DR, Shy ME, Krajewski K. Motor unit number estimate of distal and proximal muscles in CharcotMarie-Tooth disease. Muscle Nerve. 2003; 28: 161-7. 